Saudi Journal of Oral and Dental Research

Abbreviated Key Title: Saudi J Oral Dent Res

ISSN 2518-1300 (Print) |ISSN 2518-1297 (Online)

Scholars Middle East Publishers, Dubai, United Arab Emirates

Journal homepage: https://saudijournals.com/sjodr

\title{
Oral Health Behaviour and its Determinants among Dental, Medical and Nursing Students in a Tertiary Institution in Lagos State, Nigeria
} Onigbinde O. $\mathrm{O}^{1 *}$, Adenuga-Taiwo O. A ${ }^{2}$, Abah A. A ${ }^{3}$, Awotile A. $\mathrm{O}^{2}$

\begin{abstract}
${ }^{1}$ Department of Preventive Dentistry, Lagos State University College of Medicine/ Lagos State University Teaching Hospital, Ikeja, Lagos, Nigeria ${ }^{2}$ Department of Restorative Dentistry, Lagos State University College of Medicine/ Lagos State University Teaching Hospital, Ikeja, Lagos, Nigeria ${ }^{3}$ Department of Oral Pathology/ Oral Medicine, Lagos State University College of Medicine/ Lagos State University Teaching Hospital, Ikeja, Lagos, Nigeria
\end{abstract}

DOI: $10.36348 /$ sjodr.2020.v05i08.006

| Received: 02.08.2020 | Accepted: 09.08.2020 | Published: 19.08.2020

*Corresponding author: Dr. O.O. Onigbinde

\section{Abstract}

Background: Oral health entails practicing and maintenance of good oral hygiene. It is an integral part of general health. Aim: To determine the oral health behavior among dental, medical and nursing students of the Lagos State University College of Medicine, Ikeja Lagos. Nigeria. Materials and Methods: The survey was conducted among dental, medical and nursing students of Lagos State University College of Medicine, Ikeja, using a self-administered structured questionnaire, which assessed their oral health attitude and practices. The obtained data was analyzed using the Statistical Package for the Social Sciences version 21 software. Results: One hundred and thirty participated in the study. More than twenty-eight percent (28.5\%) brush twice a day, $27.7 \%$ use dental floss regularly, and only $47.7 \%$ use water to rinse after meals. About $56.9 \%$ of the medical students have never been to a dentist. A few, 7.7\% have undertaken the every 6 months dental visits and $77.7 \%$ agreed that oral hygiene was necessary for good general health. The study also showed that female students (both dental and medical) showed better oral health practices than male students. Conclusion: Although dental students exhibited better practice towards oral health, but there was a lack of adequate attitude among them. Further emphasis on oral health is necessary in undergraduate training to improve the oral health attitude and practice among dental, medical and nursing students as they will act as role models for oral health education among individuals and community at large.

Keywords: Oral health, oral hygiene, students.

Copyright @ 2020: This is an open-access article distributed under the terms of the Creative Commons Attribution license which permits unrestricted use, distribution, and reproduction in any medium for non-commercial use (NonCommercial, or CC-BY-NC) provided the original author and source are credited.

\section{INTRODUCTION}

Dental hygiene is the science and practice of the recognition, treatment, and prevention of oral diseases. Good oral hygiene is the foundation for a healthy mouth and prevents $80 \%$ of all dental problems [1]. Oral diseases are still the most prevalent problems that affect the overall health of human beings [2]. Periodontitis and dental caries are two major oral problems affecting $60 \%$ and $36 \%$ of the people respectively worldwide.

Oral health plays an important role in overall health and is an indispensable part of general health [3]. It is reported that there is a close relationship between oral diseases and systemic diseases like diabetes, crohn's disease, stroke, cardiovascular disease, metabolic syndrome, pregnancy outcomes and obesity $[4,5]$. Oral problems, on one hand, could result in a pro-inflammatory state, that may initiate or worsen a systemic disease [6], while, systemic disorders might be responsible for the development of oral problems [7, 8].

However, oral health care is always neglected despite the importance of oral health in general health [9]. Given the importance of oral health in the whole body and the high prevalence of oral diseases, the joint effort of dentists and clinicians is essential to people's health, and it should be integrated as part of the comprehensive health promotion $[10,11]$.

Oral care practices such as brushing with fluoride toothpaste, dental flossing, regular dental check-ups including cleaning the teeth professionally at least twice a year, are recommended measures for maintaining good oral health [12].

Raising public awareness about dental checkup may assist in early diagnosis of cancer and other oral diseases [13]. The population needs to receive 
information on oral diseases, risk factors and measures that can be adopted to prevent them. The change from an unhealthy attitude to a healthy attitude will occur when adequate information and motivation are provided; and adequate practices of the measures are adopted by the subject [14].

The medical professionals are more likely to encounter vulnerable populations than dental professionals, particularly Family Health and Community physicians. The behavior of oral health professionals reflects their understanding of oral preventive measures and practices, which have a great impact on the delivery of oral health to their patients $[15,16]$. Therefore, it is very important for dental, medical and nursing students to have good oral health behaviour as they will be the major providers of health services and be responsible for public oral health promotion in the future. Gender and age are key factors that may influence oral health behaviour. These have been demonstrated in a study by Folayan et al., [17].

\section{AIM OF THE STUDY}

This study, therefore, aims to determine oral health behaviour among dental, medical and nursing students in a Tertiary Institution in Lagos State, Nigeria.

\section{METHODOLOGY}

It was a cross-sectional study of oral health behaviour among medical, dental and nursing students of the Lagos State University, College of Medicine. LASUCOM, Ikeja. Lagos. Ethical clearance was obtained from the Research and Ethics Committee of Lagos State University Teaching Hospital. LASUTH, Ikeja. Lagos. The target population was the second-year students, during the academic year 2018/2019. Verbal informed consent was taken from the health professional students and responses from those who agreed to participate in the study were considered. A self-administered questionnaire was designed and distributed among 150 health professional students, out of which 130 were properly filled and therefore considered. The questionnaire consisted of three parts. The first part comprised the demographic data of students (age, gender and course of study). The second part consisted of questions related to oral hygiene practices amongst the healthcare professionals, which included: oral hygiene method used, frequency of tooth brushing, frequency of changing toothbrushes, types of tooth brushes used, tongue cleaning, use of water to rinse after meals, importance of dental visitations and relationship between oral hygiene and general health. The third part evaluated factors that determined their attitude towards oral health which included reasons for dental visit, the motivation for the last visit, reason for not visiting and also questions on dental treatment that was sought during the last visit.

\section{STATISTICAL ANALYSIS}

The data was entered using Statistical Package for Social Sciences (SPSS) version 21 for windows. Chi-square test was used for the analysis of data. Also ANOVA was used to compare the attitude and practice between students in the three groups (medical, dental, and nursing). T-test was also used to compare between males and females with respect to level of attitude and practice. $\mathrm{P}$ value was set at $\mathrm{P}<0.05$.

\section{RESULTS}

A total of 130 students completed and returned the questionnaire. Of these, $24(18.5 \%), 82(63.1 \%)$, and $24(18.5 \%)$ were dental, medical, and nursing students, respectively. There were 79 females and 51 males, with male to female ratio of $1: 1.46$. The age range of respondents was 17-30 years, and the mean age was $20.7 \pm 3.2$ years $($ Table- 1$)$.

The mean percentage scores for attitude and behavior was higher among the dental students than the mean scores for the medical and nursing students. The mean percentage scores for attitude and behavior was higher in female students than male students. The mean score for attitude was statistically significant in gender and age (Table-2).

About 115(88.5\%) of the participants in this study used toothbrush and toothpaste to clean their teeth. Flossing was used only by 36(27.7), it was more frequent in dental students $10(41.7 \%)$. Mouthwash $42(32.3 \%)$ was more frequently used compared to floss. There was a statistically significant difference in the oral hygiene methods between the groups $(\mathrm{P}=0.010)$.

About $93(71.5 \%)$ of the students brushed their teeth once a day. The dental students 11(45.8) brushed their teeth twice or more in a day than the medical and nursing students. .

Almost all, 115(88.5.4\%) of the students used the medium bristled tooth brushes for cleaning their teeth. There was a statistically significant difference between the groups $(\mathrm{P}=0.025)$

About 59(39.0\%) of the students changed their tooth brushes every 3 months. Almost all of them cleaned their tongues, but only 62(47.7\%) rinsed their mouth with water after meals (Table-3).

A total of $80.8 \%$ of the students, of which $95.8 \%$ of dental students believed that regular visit to dental surgeon is necessary, whereas only $58.3 \%$ of the medical students agreed on this fact; the difference was statistically significant $(\mathrm{p}=0.003)$. A large number of students, $74(56.9 \%)$ had never been to a dentist, and 17 $(13.1 \%)$ only went to see a dentist when in pain. 
A total of $84.6 \%$ of the students $(83.3 \%$ dental, $84.1 \%$ medical and $87.5 \%$ nursing students) knew that the purpose of tooth brushing was to clean teeth, to prevent tooth decay and odor. The entire dental (100\%),
$(73.2 \%)$ of the medical and $(70.8 \%)$ of nursing students considered oral health to be important in maintaining good general health. The difference between group was statistically significant $\mathrm{p}=0.014$ (Table-4).

Table-1: Age, gender and course of study distribution of the participants

\begin{tabular}{|l|l|}
\hline Variable & N \% \\
\hline Age & \\
$17-20$ & 8061.5 \\
$21-30$ & 5038.5 \\
Gender & \\
Female & 7960.8 \\
Male & 5139.2 \\
Course of study & \\
Dental & 2418.5 \\
Medical & 8263.1 \\
Nursing & 2418.5 \\
Total & $\mathbf{1 3 0} \mathbf{1 0 0}$ \\
\hline
\end{tabular}

Table-2: Shows the mean percentage scores for attitude and practice in relation to gender and the students' course of study

\begin{tabular}{|l|l|l|l|}
\hline Variables & Mean \pm SD & Mean percentage score \% & P value \\
\hline $\begin{array}{l}\text { Practice Score } \\
\text { Gender }\end{array}$ & & & \\
Female & $8.37 \pm 1.46$ & 69.7 & \\
Male & $7.69 \pm 1.39$ & 64.1 & 0.560 \\
Age & & & \\
$17-20$ & $7.95 \pm 1.34$ & 66.2 & 0.068 \\
$21-30$ & $8.34 \pm 1.64$ & 69.5 & \\
Course of study & & & 0.616 \\
Dental & $8.71 \pm 1.37$ & 72.6 & \\
Medical & $8.01 \pm 1.52$ & 66.7 & \\
Nursing & $7.79 \pm 1.21$ & 64.9 & \\
Total & $\mathbf{8 . 1 0} \pm \mathbf{1 . 4 7}$ & $\mathbf{6 7 . 5}$ & \\
Attitude Score & & & \\
Gender & & & \\
Female & $2.46 \pm 1.48$ & 41.0 & \\
Male & $2.45 \pm 1.55$ & 40.8 & \\
Age & & & \\
17-20 & $2.05 \pm 1.16$ & 34.2 & \\
21-30 & $3.10 \pm 1.76$ & 51.7 & \\
Course of study & & & \\
Dental & $2.87 \pm 1.40$ & 47.8 & \\
Medical & $2.47 \pm 1.54$ & 41.2 & \\
Nursing & $1.96 \pm 1.40$ & 32.7 & \\
Total & $\mathbf{2 . 4 5} \pm \mathbf{1 . 5 1}$ & $\mathbf{4 0 . 8}$ & \\
\hline & & & \\
\end{tabular}


Onigbinde O. O et al; Saudi J Oral Dent Res, August, 2020; 5(8): 387-393

Table-3: Oral hygiene practices among the health professionals

\begin{tabular}{|c|c|c|c|c|c|}
\hline Variables & Course o & Study & & & \\
\hline & Dental & $\begin{array}{l}\text { Medical } \\
\text { No } \%\end{array}$ & Nurses & Total & $\mathrm{P}$ value \\
\hline Tooth cleaning Tool & & & & & \\
\hline Toothbrush & $22(91.7)$ & $70(85.4)$ & $23(95.8)$ & $115(88.5)$ & 0.319 \\
\hline Both & $2(8.3)$ & $5(6.1)$ & $1(4.2)$ & $8(6.1)$ & \\
\hline Chewing sticks & $0(0.0)$ & $7(8.5)$ & $0(0.0)$ & $7(5.4)$ & \\
\hline Frequency of brushing & & & & & \\
\hline Once & $13(54.2)$ & $62(75.6)$ & $18(75.0)$ & $93(71.5)$ & 0.113 \\
\hline Twice & $11(45.8)$ & $20(24.4)$ & $6(25.0)$ & $37(28.5)$ & \\
\hline Other cleaning aids & & & & & \\
\hline Floss & $10(41.7)$ & $25(30.5)$ & $1(4.2)$ & $36(27.7)$ & $0.010^{*}$ \\
\hline Mouthwash & $5(20.8)$ & $22(26.8)$ & $15(62.5)$ & $42(32.3)$ & \\
\hline Toothpick & $2(8.3)$ & $11(13.4)$ & $1(4.2)$ & $14(10.8)$ & \\
\hline Others & $7(29.2)$ & $24(29.3)$ & $7(29.1)$ & $38(29.2)$ & \\
\hline Types of brushes used & & & & & \\
\hline Soft & $2(8.3)$ & $11(12.4)$ & $9(37.5)$ & $22(16.9)$ & $0.025^{*}$ \\
\hline Medium & $21(87.5)$ & $54(65.9)$ & $11(45.8)$ & $86(66.2)$ & \\
\hline Hard & $1(4.2)$ & $15(18.3)$ & 4 16.7) & $20(15.4)$ & \\
\hline Nothing & $0(0.0)$ & $2(2.4)$ & $0(0.0)$ & $2(1.5)$ & \\
\hline Frequency of tooth brush Change & & & & & \\
\hline Months & $2(8.3)$ & $16(19.5)$ & $1(4.2)$ & $19(14.6)$ & \\
\hline 3months & $15(62.5)$ & $32(39.0)$ & $12(50.0)$ & $59(39.0)$ & 0.306 \\
\hline When brush fray & $3(12.5)$ & $16(19.5)$ & $5(20.8)$ & $24(18.5)$ & \\
\hline Occasionally & $4(16.7)$ & $18(22.0)$ & $6(25.0)$ & $28(21.5)$ & \\
\hline Tongue cleaning & & & & & \\
\hline Yes & $23(95.8)$ & $81(98.8)$ & $24(100.0)$ & $128(98.5)$ & 0.508 \\
\hline No & $1(4.2)$ & $1(1.2)$ & $0(0.0)$ & $2(1.5)$ & \\
\hline Water rinsing & & & & & \\
\hline Yes & $12(50.0)$ & $37(45.1)$ & $13(54.2)$ & $62(47.7)$ & 0.715 \\
\hline No & $12(50.0)$ & $45(54.9)$ & $11(45.8)$ & $68(52.3)$ & \\
\hline
\end{tabular}

Table-4: Attitude of subjects toward professional dental care

\begin{tabular}{|l|l|l|l|l|l|}
\hline \multicolumn{2}{|c|}{ Variables } & \multicolumn{5}{c|}{ Course of study } \\
\hline Regular dental visit important & Dental & Medical & Nurses & Total & P value \\
Yes & & & & & \\
No & $23(95.8)$ & $68(82.9)$ & $14(58.3)$ & $105(80.8)$ & $0.003^{*}$ \\
Ever visited a dentist & $1(4.2)$ & $14(17.1)$ & $10(41.7)$ & $25(19.2)$ & \\
Yes & & & & & \\
No & $10(41.7)$ & $38(46.3)$ & $8(33.3)$ & $56(43.1)$ & 0.433 \\
Frequency of dental visit & $14(58.3)$ & $44(53.7)$ & $16(66.7)$ & $74(56.9)$ & \\
6-12months & & & & & \\
When in pain & $3(12.5)$ & $7(8.5)$ & $0(0.0)$ & $10(7.7)$ & 0.225 \\
Occasionally & $4(16.7)$ & $8(9.8)$ & $5(20.8)$ & $17(13.1)$ & \\
Never & $3(12.5)$ & $23(28.0)$ & $3(12.5)$ & $29(22.3)$ & \\
Reason for brushing & $14(58.3)$ & $44(53.7)$ & $16(66.7)$ & $74(56.9)$ & \\
For clean and bright teeth & & & & & \\
To prevent decay & $0(0.0)$ & $8(9.8)$ & $1(4.2)$ & $9(6.9)$ & 0.308 \\
To prevent odor & $2(8.3)$ & $2(2.4)$ & $0(0.0)$ & $4(3.1)$ & \\
All the Three & $2(8.3)$ & $3(3.7)$ & $2(8.3)$ & $7(5.4)$ & \\
Oral hygiene necessary for general health & $20(83.3)$ & $69(84.1)$ & $21(87.5)$ & $110(84.6)$ & \\
Yes & $24(100.0)$ & $60(73.2)$ & $17(70.8)$ & $101(77.7)$ & \\
No & $0(0.0)$ & $22(26.8)$ & $7(29.2)$ & $29(22.3)$ & $0.014 *$ \\
\hline
\end{tabular}




\section{DISCUSSION}

The present study revealed that $88.5 \%$ of the students used toothpaste and toothbrush and 5.4\% used chewing sticks to clean their teeth. This was comparable to $78.7 \%$ of the students that used toothpaste and $16.3 \%$ that used toothbrush and miswak in a study by Al Subait [18]. However Bashiru et al., [19] reported $100 \%$ and Kumar et al., [20] reported that $96.6 \%$ students in their study used toothbrushes and paste for cleaning.

A total of $28.5 \% \quad(45.8 \%$ dental, $24.8 \%$ medical and $25.0 \%$ nursing) students brushed twice a day in our study. A similar result was reported by Benjamin et al., [21] in a study conducted at the University of Nairobi, which showed that $39.0 \%$, of which $(27.5 \%$ dental and $39 \%$ medical) students brushed twice daily. A study by Kumar et al., [20] reported that $65.3 \%$ of which, $(77.3 \%$ dental and $53.3 \%$ medical) students brushed twice daily. About approximately $60 \%$ of the students cleaned their teeth twice daily in Bashiru et al., [19] study and the values were much lower than those reported in our study $(28.5 \%)$.

Flossing of teeth is as much required as brushing, for complete cleanliness of teeth. In this study $27.7 \%$ of the students $(41.7 \%$ dental, $30.5 \%$ medical and $4.2 \%$ nursing), students flossed regularly. This was comparable with the report of Al Subait et al., [18] where $24.5 \%$ of the students $(24.4 \%$ medical, $23.3 \%$ dental and $31.2 \%$ nursing) in the study flossed regularly. However, Kumar et al., [20] reported that $13.3 \%$ of the students, $(16.0 \%$ of the medicals and $10.6 \%$ of dental students) flossed regularly and $14.2 \%$ of dental and $3.0 \%$ of medical students flossed in Yao et al., study [2]. In Azodo et al., study [22] only 2.9\% of the medical students flossed regularly. This showed that the dental floss was not very popular among the students due to lack of awareness of its use and the benefits of flossing on oral health.

In this study, toothbrush renewal of every 3 months was $39.0 \%$ (39.0\% of medical, $62.5 \%$ of dental and $50.0 \%$ for nursing students) which was similar to the $28.8 \%$ from Bashiru et al., [19] and $41.1 \%$ (44.2\% medical, $36.7 \%$ dental and $45.8 \%$ nursing students reported by Al Subait et al., [18]. All were lower than 47.7\% and 62.9\% from Azodo et al., [22] and Gupta et al., studies [24]. Fraying was the most common reason cited for the renewal of toothbrush in all the groups. This result was in accordance with the results of Gopikrishna et al., [1]. This infers that these students are unaware of the fact that prolonged usage of toothbrushes not only decreases effectiveness in cleaning of plaque, but also causes trauma to gingival tissue. They should be educated about the importance of changing of toothbrushes at regular intervals.
Medium-textured toothbrushes are considered gum and oral tissue friendly [25]. The use of mediumtextured toothbrushes by the students was close to $66 \%$ in this study, similar to previous studies [19, 24, 25], but contrary to the $30.9 \%$ reported by Azodo et al in their study [22].

More than $60 \%$ of the population in Al Subait et al., [18] study cleaned their mouth after eating a meal; however, only $47.7 \%$ rinsed their mouth in our study. Almost all the participants, $98.5 \%$ in this study cleaned their tongues, similar to $87.2 \%$ in Gupta et al., [24] study on medical and nursing students in Raipur India. Daya et al., [26] recorded $100 \%$ of tongue cleaning from their study on dental students, while about, $56.4 \%$ of the students cleaned their tongue in $\mathrm{Al}$ Subait et al., study [18].

A total of $95.8 \%$ of our dental, $82.9 \%$ of medical and $58.3 \%$ of nursing students felt the necessity of regular visits to a dental surgeon. This is similar to the report of Kumar et al., [20] with $89.33 \%$ of dental and $81 \%$ of medical students. In Al Subait et al., [18] study, more than $80 \%$ of the students believed that visiting dentists before having a dental problem is important.

In this study, $(43.1 \%)$ reported dental attendance, while $33 \%$ and $25.1 \%$. reported dental attendance among students in previous studies $[19,23]$ This conforms with the fact that regular dental attendance is uncommon in developing countries mainly because the populations prefer symptomatic dental attendance to preventive dental attendance [23]. However, this was contrary to $78 \%$ and $71.9 \%$ reported among students in other studies [1,9].

Majority of the students in the present study agreed that regular dental visit was necessary but less than $7.7 \%$ of the students practiced the recommended six (6) monthly dental visits. Other studies reported that $4 \%$ [25] and $15.4 \%$ [1] of the students visited on the recommended 6 monthly visits. About $13 \%$ of the students in our study visited the dentists for relief of pain. About $38.7 \%$ and $50 \%$ were reported by some studies $[1,25]$. This reflected the poor attitude of the students to oral health care.

On evaluating the attitude towards oral health, in this study, about $84.6 \%$ of students were of the opinion that the purpose of brushing their teeth is to have clean teeth, to get rid of bad breath and to have healthy teeth. Similar to the opinion from $60.0 \%$ of the students in Al Subait et al., study [18]. A total of $92.67 \%$ of the students $(96.67 \%$ dental and $88.67 \%$ medical) believed that the purpose of tooth brushing was to prevent tooth decay and gum disease in a study by Kumar et al., [20] The leading principal reason for teeth cleaning was fresh breath, $52.1 \%$ was reported by medical students in Azodo et al., study [23]. 
In our study, most of the dental (100.0\%), medical $(73.2 \%)$ and $70.8 \%$ of nursing students considered oral health to be important in maintaining good general health, and this is compatible with the findings of previous studies [1, 18, 20, 27].

In the present study, the total mean percentage scores for behavior were more than $65 \%$ among the students. Although about $65 \%$ of the students showed positive behavior toward oral health care, $35 \%$ of the students showed negative oral health behavior. This negative behavior was particularly related to the frequency of tooth brushing, the use of dental floss and mouth rinsing with water after meals, and this is suggestive of lack of adequate oral care among the students. This was similar to Bashiru et al., [19] report on behavior of students in Port Harcourt.

About $40 \%$ gave the correct response to attitude questions. The attitude of the students to oral care was inadequate. This indicates that about $60 \%$ of the students showed negative attitude toward oral health care. This negative behavior was particularly related to dental visit and the recommended 6 monthly visits. This was contrary to the report of Bashiru et al., [19].

In this study, female students had better attitude and practice compared with male students. Similar to other studies on students [18-20]. The dental students had significantly better attitude and practice about oral hygiene practices compared with the other groups. In Kumar et al., study [20], the medical had better practice of oral care than the dental and nursing students and in Al Subait et al., [18] the nursing students had better attitude and practice than the dental and medical students.

\section{CONCLUSION}

Dental, medical and nursing students must be taught oral health education during their training. They must be equipped with the knowledge and skill of oral health. Attitude, the practice and dental attendance are all important in maintaining optimal oral health. The knowledge gained by the students would be used for future practices, disseminating information and care to their patients and the community at large.

The students' background variables, such as gender, age, attitude and practice towards oral health show differences in preventive dental care. This should be addressed in future researches, to identify how and why such background variables are significant determinants of oral health behaviour among the medical, dental and nursing students despite their professional training.

\section{REFERENCES}

1. Gopikrishna, V., Bhaskar, N. N., Kulkarni, S. B., Jacob, J., \& Sourabha, K. G. (2016). Knowledge, attitude, and practices of oral hygiene among college students in Bengaluru city. Journal of Indian Association of Public Health Dentistry, 14(1), 75-79.

2. Yao, K., Yao, Y., Shen, X., Lu, C., \& Guo, Q. (2019). Assessment of the oral health behavior, knowledge and status among dental and medical undergraduate students: a cross-sectional study. BMC oral health, 19(1), 1-8.

3. Baiju, R. M., Peter, E. L. B. E., Varghese, N. O., \& Sivaram, R. (2017). Oral health and quality of life: current concepts. Journal of clinical and diagnostic research: JCDR, 11(6), ZE21-ZE26.

4. Nazir, M. A. (2017). Prevalence of periodontal disease, its association with systemic diseases and prevention. International journal of health sciences, 11(2), 72-80.

5. Winning, L., \& Linden, G. J. (2017). Periodontitis and systemic disease: association or causality?. Current oral health reports, 4(1), 1-7.

6. Tavares, M., Calabi, K. A. L., \& San Martin, L. (2014). Systemic diseases and oral health. Dental Clinics, 58(4), 797-814.

7. Tanaka, T. I., \& Geist, S. M. R. Y. (2012). Dermatomyositis: a contemporary review for oral health care providers. Oral Surgery, Oral Medicine, Oral Pathology and Oral Radiology, 114(5), e1-e8.

8. Zalewska, A., Waszkiewicz, N., Szajda, S. D., \& Waszkiel, D. (2011). Impact of salivary flow and lysozyme content and output on the oral health of rheumatoid arthritis patients. Advances in Hygiene \& Experimental Medicine/Postepy Higieny $i$ Medycyny Doswiadczalnej, 65:40-45.

9. Bradbury-Jones, C., Innes, N., Evans, D., Ballantyne, F., \& Taylor, J. (2013). Dental neglect as a marker of broader neglect: a qualitative investigation of public health nurses' assessments of oral health in preschool children. BMC public health, 13(1), 370.

10. Rabiei, S., Mohebbi, S. Z., Patja, K., \& Virtanen, J. I. (2012). Physicians' knowledge of and adherence to improving oral health. BMC Public Health, 12(1), 1-9.

11. Baseer, M. A., Alenazy, M. S., AlAsqah, M., AlGabbani, M., \& Mehkari, A. (2012). Oral health knowledge, attitude and practices among health professionals in King Fahad Medical City, Riyadh. Dental research journal, 9(4), 386-392.

12. Iwuala, S. O., Umeizudike, K. A., Ozoh, O. B., \& Fasanmade, O. A. (2015). Oral self-care practices, dental attendance and self-perceived oral health status among internal medicine residents in Nigeria. Eur J Gen Dent. 4:79-86.

13. Emmanuel, A., \& Chang'endo, E. (2010). Oral health related behaviour, knowledge, attitudes and beliefs among secondary school students in Iringa municipality. Dar Es Salaam Medical Students Journal, 17(1), 24-30. 
14. Attaullah, K. M., Ali, K. A. (2010). Oral health related knowledge, attitude and practices among patients - a study. Pakistan Oral \& Dental Journal. 30:186-19.

15. Pacauskiene, I. M., Smailiene, D., Siudikiene, J., Savanevskyte, J., \& Nedzelskiene, I. (2014). Selfreported oral health behavior and attitudes of dental and technology students in Lithuania. Stomatologija, 16(2), 65-71.

16. Ahamed S, Moyin S, Punathil S, Patil NA, Kale VT, Pawar G. Evaluation of the Oral health knowledge, attitude and behavior of the preclinical and clinical dental students. Journal of international oral health: JIOH. 2015;7(6):65-70.

17. Folayan, M. O., Khami, M. R., Folaranmi, N., Popoola, B. O., Sofola, O. O., Ligali, T. O., ... \& Orenuga, O. O. (2013). Determinants of preventive oral health behaviour among senior dental students in Nigeria. BMC oral health, 13(1), 28 .

18. Al Subait, A., Ali, A., Alehaideb, A., Alshebel, AR., Alqahtani, A. W., \& El-Metwally, A. (2017). Knowledge, Attitudes and Practices Related to Oral Health among University Students in Saudi Arabia; a Cross-Sectional Study. J Dent \& Oral Disord. 3(6): 1-8.

19. Bashiru, B. O., \& Omotola, O. E. (2016). Oral health knowledge, attitude and behavior of medical, pharmacy and nursing students at the University of Port Harcourt, Nigeria. Journal of Oral Research and Review, 8(2), 66-71.

20. Kumar, H., Behura, S. S., Ramachandra, S., Nishat, R., Dash, K. C., \& Mohiddin, G. (2017). Oral health knowledge, attitude, and practices among dental and medical students in Eastern India-A comparative study. Journal of
International Society of Preventive \& Community Dentistry, 7(1), 58-63.

21. Benjamin, S. N., Gathece, L. W., \& Wagaiyu, E. G. (2016). Knowledge, attitude and use of mouthwash among dental and medical students of the University of Nairobi. Int $J$ Dent Oral Health, 2(5), 1-6.

22. Azodo, C. C., \& Ogbebor, O. G. (2018). Dental attendance and teeth cleaning characteristics among medical and pharmacy students. Indian Journal of Multidisciplinary Dentistry, 8(1), 7-12.

23. Azodo, C. C., \& Abanaba, O. (2020). Oral hygiene-related knowledge and attitude among nigerian medical and pharmacy students: a crosssectional study. Journal of Oral Research and Review, 12(1), 1-5.

24. Gupta, V. (2020). Assessment of oral hygiene practices among medical students. Int $J$ Community Med Public Health. 7(3):1170-1177.

25. Oyetola, E. O., Okunola, I. E., Adedigba, M. A., Nwhator, S. O., Soyele, O. O., Fadeju, A. D., \& Owotade, F. J. (2016). Oral health practices and oral hygiene status of undergraduate students at Ile-Ife, Nigeria. Nigerian Journal of Health Sciences, 16(2), 76-81.

26. Daya, D., Teja, U., Paturu, D. B., Reddy, B. V. R., Nagarakanti, S., \& Chava, V. K. (2017). Evaluation of oral-hygiene awareness and practice among dental students. Journal of Dr. NTR University of Health Sciences, 6(1), 24-28.

27. Pradhan, D., Kumar, J., Shavi, G. R., Pruthi, N., Gupta, G., \& Singh, D. (2016). Evaluating the oral hygiene knowledge, attitude and practices among dental and medical students in Kanpur City. Natl $J$ Integr Res Med, 7, 73-76. 